\title{
Contribuição da inclusão de polpa cítrica e casca de soja para a qualidade da silagem de resíduo úmido de cervejaria
}

\author{
[Contribution of citrus pulp and soybean hulls for silage quality of brewery waste] \\ G.F. Greghi ${ }^{1}$, B. Barcelos ${ }^{1 *}$, A. Saran Netto ${ }^{2}$, F.G. Vilela ${ }^{2}$, P.H.M. Rodrigues ${ }^{3}$, C.T. Marino ${ }^{3}$ \\ ${ }^{1}$ Aluna de pós-graduação - Universidade de São Paulo - FZEA-USP - Pirassununga, SP \\ ${ }^{2}$ Universidade de São Paulo - FZEA-USP - Pirassununga, SP \\ ${ }^{3}$ Universidade de São Paulo - FMVZ-USP - Pirassununga, SP
}

\begin{abstract}
RESUMO
Com o objetivo de avaliar a produção da silagem e o uso de aditivos no processo de ensilagem do resíduo úmido de cervejaria, foram realizados 5 tratamentos: controle $(\mathrm{C}$ : ensilagem de $100 \%$ de resíduo úmido de cervejaria); PC15 (15\% de polpa cítrica); PC30 (30\% de polpa cítrica); CS15 (15\% de casca de soja); CS30 (30\% de casca de soja) - com base na matéria fresca do resíduo de cervejaria. As silagens foram confeccionadas em baldes plásticos com $252 \mathrm{~mm}$ de altura e $245 \mathrm{~mm}$ de diâmetro $\left(0,06174 \mathrm{~m}^{3}\right)$, e amostras foram coletadas para análises bromatológicas, $\mathrm{pH}$, nitrogênio amoniacal, digestão in vitro de matéria seca, ácidos orgânicos e perfil microbiológico. Os resultados foram analisados pelo programa computacional Statistical Analysis System (Statistical..., 1985), sendo verificada a normalidade dos resíduos pelo Teste de Shapiro-Wilk (PROC UNIVARIATE), e as variâncias, pelo Teste de Hartley. Os efeitos dos níveis de adição foram separados por meio de contrastes polinomiais utilizando o nível de significância de $5 \%$. Houve aumento do teor de matéria seca, carboidratos solúveis, ácido lático, digestão in vitro de matéria seca, da população de bactérias ácido láticas e redução do pH, ácido butírico, propiônico e nitrogênio amoniacal a partir das inclusões de polpa cítrica e casca de soja, sendo os melhores resultados encontrados para o tratamento com inclusão de $30 \%$ de polpa cítrica $(\mathrm{P}<0,05)$. A ensilagem do bagaço de malte por si só é uma alternativa para o produtor rural como suporte alimentar e confecção de silagem de qualidade que pode ser incrementada com o uso de aditivos a serem avaliados de acordo com a relação custo-benefício para eficiência da produção.
\end{abstract}

Palavras-chave: aditivos, bromatológico, digestão in vitro de matéria seca, fermentação, microbiológico

\begin{abstract}
In order to evaluate the production and use of silage additives in ensiling process of brewery residue were distributed in a completely randomized 5 treatments and 4 replicates: control (C: 100\% silage brewery residue); PC15 (15\% citrus pulp), PC30 (30\% citrus pulp), CS15 (15\% soybean hulls), CS30 (30\% soybean hulls) - based on the fresh matter brewer. The material was ensiled in plastic buckets with $252 \mathrm{~mm}$ height and $245 \mathrm{~mm}$ in diameter $\left(0.06174 \mathrm{~m}^{3}\right)$ and samples were collected for chemical analyzes, pH, ammonia nitrogen, digestion "in vitro" dry matter, organic acids and microbial profile. The results were analyzed by the computer program Statistical Analysis System (Statistical..., 1985), and verified the normality of residuals by the Shapiro-Wilk (PROC univariate) and the variances for the Test of Hartley. The effects of addition levels were separated by means of contrasts polynomial using a significance level of 5\%. There was an increase in dry matter content, soluble carbohydrates, lactic acid, digestion "in vitro" dry matter, the population of lactic acid bacteria and reduced $\mathrm{pH}$, butyric acid, propionic acid and ammonia nitrogen from the inclusion of citrus pulp and peel soybean, being the best results for the treatment including $30 \%$ of citrus pulp $(P<0.05)$. The ensiling of spent grain by itself is an alternative for farmers as food support and making silage quality can be enhanced with the use of additives to be evaluated according to the cost: benefit ratio for production efficiency.
\end{abstract}

Keywords: additives; chemical analyzes, digestion "in vitro" dry matter; fermentation microbiology

Recebido em 26 de outubro de 2012

Aceito em 20 de agosto de 2013

*Autor para correspondência (corresponding author)

E-mail: brendabarcelos@yahoo.com.br 


\section{INTRODUÇÃO}

Segundo indicadores da UNCTAD (2010), a Conferência das Nações Unidas para o Comércio e Desenvolvimento, o Brasil será o maior país agrícola do mundo em dez anos. Hoje, o agronegócio já representa uma das atividades que mais contribuem para o crescimento do nosso país, trata-se da principal locomotiva da economia brasileira e responde por um em cada três reais gerados no país.

Contudo, aliada à evolução, desenvolvimento e transformação de alimentos, está a geração de muitos resíduos, sendo estes um dos principais problemas ambientais não só no Brasil, mas no mundo (Giordano, 2000).

Os resíduos gerados nos processos agroindustriais, se não receberem destinação adequada, podem proporcionar problemas ambientais. Dentre esses resíduos, encontra-se o resíduo úmido de cervejaria, um importante subproduto da indústria de cervejaria que, pelo seu considerável valor proteico, energético e mineral, pode ser amplamente utilizado na nutrição animal (Brochier e Carvalho, 2009).

A ensilagem do resíduo úmido de cervejaria figura como uma alternativa para a conservação desse material. Isso porque a fermentação pelas bactérias anaeróbicas produzem ácidos graxos voláteis, que promovem a queda do $\mathrm{pH}$, próximo de 4 , e, consequentemente, preserva a qualidade do material ensilado, com baixo custo para a sua execução.

Durante o processo da ensilagem, importantes modificações ocorrem na massa, que, se for adequadamente manipulada, resultará em fermentações desejáveis e, consequentemente, no menor volume de perdas possível. Os fenômenos ocorridos nesse processo passam por duas etapas distintas: a respiratória e a fermentativa. Após completar esta, ocorre uma estabilização do processo com aproximadamente 20 dias. Não havendo entrada de ar ou água, o material se conserva por longos períodos (Martin, 1997).

De acordo com Lavezzo e Andrade (1994), o teor de matéria seca durante o processo de ensilagem apresenta influência direta na qualidade da silagem e no volume de perdas. $\mathrm{O}$ baixo teor de matéria seca, menos de $25 \%$, pode tornar a silagem de resíduo úmido de cervejaria um meio propício para o desenvolvimento de microrganismos indesejáveis quando exposto ao ar, ocorrendo redução na qualidade do produto, podendo até causar a morte de animais no caso de algumas toxinas produzidas por certos fungos e bactérias aeróbicos. Aronovich (1999) verificou que a inclusão do rolão de milho no processo de ensilagem com bagaço de malte aumentou a matéria seca do material ensilado, o que contribuiu para a conservação da silagem.

Sabendo da grande disponibilidade do bagaço de malte com preço acessível na época das águas, atrelada à maior necessidade dos produtores na época da seca, o objetivo do projeto foi avaliar a sua associação com diferentes aditivos em níveis distintos de inclusão (polpa cítrica $15 \%$ e $30 \%$; casca de soja $15 \%$ e $30 \%$ ) durante o processo de ensilagem sobre a composição bromatológica, indicadores de qualidade, digestibilidade e perfil microbiológico.

\section{MATERIAL E MÉTODOS}

As silagens foram confeccionadas nas dependências do Departamento de Zootecnia da Faculdade de Zootecnia e Engenharia de Alimentos da Universidade de São Paulo (Campus de Pirassununga). Utilizaram-se 20 silos de laboratório confeccionados a partir de baldes plásticos com $252 \mathrm{~mm}$ de altura e $245 \mathrm{~mm}$ de diâmetro $\left(0,06174 \mathrm{~m}^{3}\right)$. Estes foram estocados verticalmente e em local abrigado.

Após pesagens dos subprodutos e misturas dos tratamentos, as respectivas massas foram colocadas dentro de cada silo e compactadas, sendo os silos fechados com tampas e, então, pesados. A compactação correspondeu à densidade de $600 \mathrm{~kg}$ de silagem $/ \mathrm{m}^{3}$. Os silos foram mantidos por 60 a 120 dias em local abrigado. A avaliação do tamanho médio de partículas foi realizada segundo metodologia das peneiras do "Penn State Particle Size Separator" proposto por Lammers (1996), definindo a porcentagem de material por diâmetro superior a $1,9 \mathrm{~cm}$, intermediário de 1,9 a $0,8 \mathrm{~cm}$, e inferior a $0,8 \mathrm{~cm}$.

O experimento foi distribuído em delineamento inteiramente ao acaso com cinco tratamentos e quatro repetições, definidas da seguinte forma: $\mathrm{C}$ : tratamento controle utilizando apenas o 
resíduo úmido de cervejaria para ensilagem; P15: inclusão de $15 \%$ de polpa cítrica; P30: inclusão de $30 \%$ de polpa cítrica; C15: inclusão de $15 \%$ de casca de soja; C30: inclusão de $30 \%$ de casca de soja. Os subprodutos agrícolas foram adicionados com base na matéria fresca do resíduo de cervejaria.

Durante o processo de ensilagem foram coletadas amostras individualizadas para a determinação dos teores de: matéria seca-MS (a 65 e $105^{\circ} \mathrm{C}$ em estufa com circulação forçada de ar (Association..., 1980); fibra em detergente neutro-FDN e fibra em detergente ácido-FDA (Van Soest, 1994); proteína bruta-PB (método Kjeldhal citado por (Association..., 1980); carboidratos solúveis (Johnson et al., 1966); e pH (medição em potenciômetro). Todas as análises foram realizadas pelo Laboratório de Nutrição Animal e Bromatologia do Departamento de Nutrição e Produção Animal da Faculdade de Medicina Veterinária e Zootecnia da USP.

Após a abertura, as massas retiradas de cada silo foram homogeneizadas, sendo uma parcela separada para determinação da matéria seca, proteína bruta, componentes da parede celular, carboidratos solúveis, poder tampão e DIVMS (Van Soest e Robertson, 1985). Outra fração foi congelada imediatamente e outra, ainda, colocada em prensa manual para a extração do suco, do qual se determinaram o pH (medição em potenciômetro) e o nitrogênio amoniacal (Foldager, 1977). Parte do suco foi congelada para posterior determinação dos ácidos orgânicos (ácidos lático, acético, propiônico e butírico) por cromatografia gasosa (Erwin et al., 1961).

Foram efetuadas análises para contagem de bactérias láticas, leveduras, enterobactérias e clostrídeos. Nos tempos 0, 2, 5, 10, 20 após a abertura dos silos foram colhidas amostras de $300 \mathrm{~g}$ de silagem de cada tratamento. O preparo das amostras incluiu a homogeneização, seguida da diluição de $10 \mathrm{~g}$ de amostra em $90 \mathrm{~mL}$ de água peptonada $0,1 \%$ e diluições seriadas até $10^{-5}$ para a posterior semeadura nos meios específicos para cada análise. A contagem de bactérias láticas foi efetuada utilizando-se ágar para Lactobacillus de
Man, Rogosa e Sharpe (MRS), com semeadura em sobrecamada e incubação a $30^{\circ} \mathrm{C}$ por três dias (Jonsson, 1991). Para a contagem de leveduras, foi utilizado ágar batata dextrose (PDA)

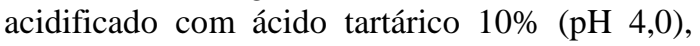
com incubação a $28^{\circ} \mathrm{C}$ por três dias (Kurtman e Fell, 1998). A contagem de enterobactérias foi realizada com uso do ágar vermelho violeta bile, com incubação a $35^{\circ} \mathrm{C}$ por dois dias (Jonsson, 1991). Para a análise de clostrídeos na silagem, utilizou-se ágar clostridial reforçado, com incubação em anaerobiose a $30^{\circ} \mathrm{C}$ por quatro dias (Tosi et al., 1982).

A utilização da silagem de resíduo úmido de cervejaria foi validada para alimentação animal utilizando cordeiros em sistema de confinamento, durante 84 dias.

Os resultados foram analisados pelo programa computacional Statistical Analysis System (Statistical..., 1985), sendo anteriormente verificada a normalidade dos resíduos pelo Teste de Shapiro-Wilk (PROC UNIVARIATE) e as variâncias comparadas pelo Teste de Hartley. Os efeitos dos níveis de adição foram separados por meio de contrastes polinomiais utilizando o nível de significância de 5\% para todos os testes realizados e a equação $\mathrm{y}=19,633+0,6279 x$ para analisar o efeito da adição sobre o teor de matéria seca.

\section{RESULTADOS E DISCUSSÃO}

Os resultados permitem inferir que as inclusões colaboram para a eficiência do processo de ensilagem do resíduo úmido de cervejaria (Tab. 1).

O teor de matéria seca aumentou de forma linear com a adição de polpa cítrica e/ou casca de soja: a cada $1 \%$ de subproduto adicionado, ocorreu incremento de $0,6279 \%$ na matéria seca, condição matematicamente expressa pela a equação de regressão $\mathrm{y}=19,633+0,6279 \mathrm{x}$. Com resultados superiores a $25 \%$ para matéria seca, o mínimo preconizado por McDonald et al. (1991), a inclusão desses subprodutos mostrou ser capaz de contribuir para o processo de produção e armazenamento do alimento. 
Tabela 1. Composição bromatológica, indicadores da qualidade de fermentação, digestibilidade in vitro de matéria seca e perfil microbiológico das silagens de resíduo de cervejaria submetidas a diferentes tratamentos.

\begin{tabular}{lccccc}
\hline \multicolumn{5}{c}{ Tratamentos } \\
\hline MS* & $\mathrm{C}$ & PC15 & PC30 & CS15 & CS30 \\
PB* & $19,89 \mathrm{e}$ & $29,00 \mathrm{c}$ & $38,80 \mathrm{a}$ & $28,58 \mathrm{~d}$ & $38,40 \mathrm{~b}$ \\
FDA* $^{*}$ & $23,45 \mathrm{a}$ & $16,46 \mathrm{c}$ & $11,93 \mathrm{e}$ & $16,88 \mathrm{~b}$ & $14,39 \mathrm{~d}$ \\
FDN* & $24,83 \mathrm{c}$ & $22,91 \mathrm{~d}$ & $21,91 \mathrm{e}$ & $34,68 \mathrm{~b}$ & $38,83 \mathrm{a}$ \\
CHOs* & $62,10 \mathrm{c}$ & $47,25 \mathrm{~d}$ & $40,67 \mathrm{e}$ & $63,64 \mathrm{a}$ & $63,00 \mathrm{~b}$ \\
pH & $1,27 \mathrm{e}$ & $4,75 \mathrm{~b}$ & $7,26 \mathrm{a}$ & $1,85 \mathrm{~d}$ & $2,31 \mathrm{c}$ \\
N-NH3* & $4,14 \mathrm{~b}$ & $3,83 \mathrm{e}$ & $3,93 \mathrm{~d}$ & $4,24 \mathrm{a}$ & $4,04 \mathrm{c}$ \\
Lático* & $1,76 \mathrm{a}$ & $0,86 \mathrm{c}$ & $0,54 \mathrm{e}$ & $1,74 \mathrm{~b}$ & $0,69 \mathrm{~d}$ \\
Acético* & $2,37 \mathrm{e}$ & $6,89 \mathrm{c}$ & $7,50 \mathrm{~b}$ & $4,02 \mathrm{~d}$ & $9,81 \mathrm{a}$ \\
Butírico* & $1,06 \mathrm{~d}$ & $1,32 \mathrm{~b}$ & $0,96 \mathrm{e}$ & $1,94 \mathrm{a}$ & $1,28 \mathrm{c}$ \\
Propiônico* & $1,22 \mathrm{a}$ & $0,01 \mathrm{~b}$ & $0,01 \mathrm{~b}$ & $0,11 \mathrm{~b}$ & $0,02 \mathrm{~b}$ \\
Etanol* & $0,36 \mathrm{~b}$ & $0,26 \mathrm{c}$ & $0,10 \mathrm{~d}$ & $0,39 \mathrm{a}$ & $0,10 \mathrm{~d}$ \\
DIVMS* & $0,17 \mathrm{e}$ & $0,59 \mathrm{~b}$ & $0,66 \mathrm{a}$ & $0,31 \mathrm{c}$ & $0,28 \mathrm{~d}$ \\
BAL** & $43,72 \mathrm{e}$ & $68,43 \mathrm{~b}$ & $73,67 \mathrm{a}$ & $44,23 \mathrm{~d}$ & $54,84 \mathrm{c}$ \\
Clostrídeos** & $3,97 \mathrm{~d}$ & $4,21 \mathrm{c}$ & $4,82 \mathrm{~b}$ & $5,10 \mathrm{a}$ & $4,82 \mathrm{~b}$ \\
Leveduras** & $3,99 \mathrm{~b}$ & $4,10 \mathrm{~b}$ & $4,71 \mathrm{~b}$ & $5,06 \mathrm{a}$ & $4,93^{\mathrm{a}}$ \\
Enterobactérias** & $1,17 \mathrm{~b}$ & $1,74 \mathrm{a}$ & $1,62 \mathrm{a}$ & - & - \\
\hline
\end{tabular}

$*(\%) ; * *(\log \mathrm{UFC} / \mathrm{g})$

Letras distintas entre si em mesma linha diferem entre si $(\mathrm{P}<0,05)$.

$\mathrm{Na}$ avaliação da proteína bruta, o maior valor foi encontrado para a silagem controle, pois o resíduo úmido de cervejaria trata-se de um alimento proteico, porém níveis elevados de proteína bruta e baixos de MS são fatores que contribuem para a produção de amônia. A polpa cítrica e a casca de soja apresentam valores menores, corroborando a literatura, pois ambos são concentrados energéticos e, ainda, detêm características interessantes para serem associadas ao resíduo: a primeira, um padrão de fermentação no rúmen que parece propiciar o uso eficiente da amônia; a segunda, alto valor em lisina (National..., 2001).

Para os teores de fibra, a casca de soja, devido à sua espessa parede celular, culminou em valores superiores de FDN. Porém, a elevada digestibilidade da fração fibrosa, atribuída principalmente aos baixos teores de lignina e elevados teores de pectina, contribui para a rápida e extensa degradação no rúmen. Segundo Valadares Filho et al. (2002), no resíduo úmido de cervejaria, apenas $33 \%$ do FDN podem ser considerados como fibra efetiva, ou seja, embora contribua para a porção fibrosa da dieta, ele não deve ser considerado um substituto para as forragens.

Para os valores de carboidratos solúveis, apenas os tratamentos com inclusão de polpa cítrica apresentaram valores considerados ideais (segundo Haigh (1990), a concentração mínima é de 2,5 a $3 \%$ na MS). Contudo, acredita-se que os baixos valores sejam decorrentes do consumo durante a ensilagem, pois a análise foi realizada ao final do processo e os indicadores de qualidade ( $\mathrm{pH}$, ácidos orgânicos, etanol e nitrogênio amoniacal) de todos os tratamentos apresentaram valores próximos aos desejáveis registrados na literatura, indicando que houve fermentação pelas bactérias anaeróbicas, produção de ácidos graxos voláteis, queda do $\mathrm{pH}$ e, consequentemente, preservação da qualidade do material ensilado.

Quanto aos ácidos orgânicos, o lático é o mais forte e o maior responsável pelo abaixamento do $\mathrm{pH}$ para a faixa ideal de 3,8-4,2. Neste experimento, o maior valor foi para a inclusão de casca de soja a 30\%. Para os teores dos ácidos acético, butírico, propriônico e etanol, a afirmação de Sprague e Leparulo (1995) de que, 
à medida que aumenta a quantidade de substrato de fácil fermentação, a silagem resultante apresenta-os em menor concentração, evidencia o benefício das inclusões sobre a produção dos ácidos, sobretudo na menor produção de butírico, mas não sobre a de etanol, para a qual o menor valor foi para a silagem controle.

Os teores de nitrogênio amoniacal encontrados nas silagens confeccionadas neste estudo mostraram que, para todas as silagens, houve baixo desdobramento de proteínas, o qual foi ainda menor com as inclusões, sobretudo na inclusão de polpa cítrica a $30 \%(\mathrm{P}<0,05)$, a qual também apresentou o melhor resultado para a digestibilidade in vitro da matéria seca $\mathrm{e}$ evidenciou a relação negativa entre a eficiência da digestão e os valores de FDA e FDN.

Os resultados apresentados na Tabela 1 permitem observar que houve condições para crescimento adequado de bactérias láticas nas silagens, sendo superior para o tratamento CS15, mas ainda assim inferior aos valores encontrados por Souza et al. (2010) em trabalhos com resíduo de cervejaria in natura, ensilado pré-seco ao sol e com ou sem drenagem de efluentes. Segundo McDonald et al. (1991), o número de bactérias ácido-láticas requerido para que ocorra acentuada queda de $\mathrm{pH}$ é de cerca de 8,0 log/g no momento da ensilagem. Entretanto, diversos autores têm observado populações iniciais entre 3,7 e $6,3 \mathrm{log} / \mathrm{g}$ em diversos materiais, sem provocarem alterações na conservação do material ensilado (Souza et al., 2010). Sendo assim, tanto o controle quanto os tratamentos apresentaram resultados favoráveis para a adequada conservação do alimento.

Além desses microrganismos desejáveis, pode haver o desenvolvimento de microrganismos prejudiciais à silagem; entre eles, os clostrídeos, leveduras e enterobactérias.

Pela análise dos dados da Tabela 1, pode-se inferir que a presença de esporos de clostrídeos foi inferior e semelhante para o controle e PC15 $(\mathrm{P}<0,05)$. Os resultados estão acima do relatado por Jobim et al. (1999), que encontraram valores entre 0,1 e $0,2 \log \mathrm{UFC} / \mathrm{g}$ em silagens de espigas e grãos de milho, respectivamente. Esses microrganismos fermentam açúcares, ácido lático e aminoácidos, produzindo ácido butírico e aminas, e resulta em perdas significativas de matéria seca, os produtos da fermentação reduzem a palatabilidade, além de diminuir a estabilidade da silagem (Mahanna, 1994; Rotz e Muck, 1994). O pH no qual a atividade dos clostrídeos cessa está relacionado ao teor de matéria seca da silagem. Isso está ligado ao fato de que os clostrídeos são sensíveis ao aumento da pressão osmótica (Woolford, 1972). Segundo Muck (1988) e Mahanna (1994), os clostrídeos tornam-se menos tolerantes ao aumento da pressão osmótica com a redução do $\mathrm{pH}$ da massa ensilada, tanto que o tratamento PC15 apresentou menor valor de $\mathrm{pH}$.

Quanto ao desenvolvimento de leveduras, os valores encontrados corroboram os de Souza et al. (2010). Uma vez que silagens com contagem de leveduras superior a 5,0 log UFC/g de silagem são altamente suscetíveis à deterioração (Woolford, 1984; Woolford, 1990), pode-se classificar as silagens avaliadas no presente experimento como estáveis, pois as leveduras são os principais agentes responsáveis pela deterioração aeróbia das silagens (Woolford, 1990; O'Kiely e Muck, 1992) por utilizarem açúcares e também ácido lático, empreendendo competição com as bactérias ácido-láticas no início do processo fermentativo, formando principalmente etanol, que não tem valor preservativo para a silagem, com agravante de ocasionar perdas de MS e de energia (Rotz e Muck, 1994).

Com relação ao desenvolvimento de enterobactérias, pode-se verificar que não houve crescimento para o C, CS15 e CS, e os valores encontrados para PC15 e PC30 estão abaixo do encontrado por outros autores que registraram 1,$3 ; 2,2 ; 3,2 ;$ e 4,2 log UFC/g de silagem de grãos úmidos de milho, amostrada, respectivamente, na abertura dos silos e a 2, 4 e 6 dias de aeração (Jobim et al., 1999).

\section{CONCLUSÕES}

A ensilagem do bagaço de malte por si só é uma alternativa para o produtor rural como suporte alimentar e geração de um produto de qualidade, mas pode ser incrementada com o uso de aditivos. A adição de polpa cítrica e casca de soja foi eficiente para conservação e qualidade do alimento, contribuiu para o aumento do teor de matéria seca, carboidratos solúveis, ácido lático, digestibilidade in vitro de matéria seca, da 
população de bactérias ácido-láticas e a redução do pH, ácido butírico, ácido propiônico e nitrogênio amoniacal, sendo os melhores resultados encontrados, em conjunto, para o tratamento da silagem com inclusão de $30 \%$ de polpa cítrica $(\mathrm{P}<0,05)$. Diante da qualidade demonstrada pelos valores encontrados neste experimento, é relevante que a decisão pela adoção do uso de aditivos e seus níveis considere a relação custo-benefício dentro de uma estratégia de produção em busca da eficiência.

\section{REFERÊNCIAS}

ARONOVICH, M. Composição bromatológica e degradabilidade de silagens de resíduo úmido de cervejaria.1999. 66f. Dissertação (Mestrado em Zootecnia) - Universidade Federal de Lavras, Lavras.

ASSOCIATION of official analytical chemisttsAOAC. Official Methods of Analysis. 10.ed. Washington, D.C., 1980. 1015p.

BROCHIER, M.A.; CARVALHO, S. Aspectos ambientais, produtivos e econômicos do aproveitamento de resíduo úmido de cervejaria na alimentação de cordeiros em sistema de confinamento. Cienc. Agrotecnol., v.33, p.13921399, 2009.

ERWIN, E.S.; MARCO, G.J.; EMERY, E.M. Volatile fatty acid analyses of blood and rumen fluid by gas chromatography. J. Dairy Sci., v.44, p.1768-1771, 1961.

FOLDAGER, J. Protein requirement and non protein nitrogen for high producing cow in early lactation. 1977. Ph.D. thesis- Michigan State University, East Lasing, MI .

GIORDANO, S.R. Gestão ambiental no sistema agroindustrial. In: ZYLBERSZTAJN, D.; NEVES, M.F. (Orgs.). Economia e gestão de negócios agroalimentares: indústria de alimentos, indústria de insumos, produção agropecuária, distribuição. São Paulo: Pioneira, 2000. p.255281.

HAIGH, P.M. Effect of herbage water-soluble carbohydrate content and water conditions at ensilage on the fermentation of grass silages made on commercial farms. Grass and Forage Sci., v.45, p.263-271, 1990.
JOBIM, C.C.; REIS, R.A.; RODRIGUES, L.R.A. et al. Desenvolvimento de microrganismos durante a utilização de silagens de grãos úmidos de milho e de espigas de milho sem brácteas. Acta Scientiarum, v.21, p.671-676, 1999.

JOHNSON, R.R.; BALWANI, T.L.; JOHNSON, L.J. et al. Corn plant maturity. Effect on in vitro cellulose digestibility and soluble carbohydrate content. J. Anim. Sci., v.25, p.617-623, 1966.

JONSSON, A. Growth of Clostridium tyrobutyricum during fermentation and aerobic deterioration of grass silage. J. Sci. Food and Agriculture, v.54, p.557-568, 1991.

KURTMAN, C.P.; FELL, J.W. The yeast: a taxonomic study. Amsterdam: Elsevier, 1998. $1055 \mathrm{p}$.

LAMMERS, B.P.; BUCKMASSTER, D.R.; HEINRICHS, E.J. A simple method for the analysis of particle sizes of forages and total mixed rations. J. Dairy Sci., v.79, p.922-928, 1996.

LAVEZZO, W.; ANDRADE, J.B. Conservação de forragens: feno e silagem. In: SIMPÓSIO BRASILEIRO DE FORRAGEIRAS E PASTAGENS, 1994, Campinas. Anais... Campinas: CNBA, 1994. p.105-166.

MAHANNA, B. Proper management assures high-quality silage, rains. Feedstuffs, v.10, p.1259, 1994.

MARTIN, L.C.T. Bovinos - volumosos suplementares. São Paulo: Nobel, 1997. p.82138.

McDONALD, P.; HENDERSON, A.R.; HERON, S. The biochemistry of silage. 2.ed. Marlow: Chalcombe Publications, 1991. p.340.

MUCK, R.E. Factors influencing silage quality and their implications for management. J. Dairy Sci., v.71, p.2992-3002, 1988.

NATIONAL Research Council - NRC. Nutrient Requirements of Dairy Cattle. 7th Ver. Ed. Washington - D.C.:National Academy Press, 2001.p.408.

O'KIELY, P.; MUCK, R.E. Aerobic deterioration of lucerne (Medicago sativa) and maize (Zea mays) silage effects of yeast. J. Anim. Sci., v.59, p.139-144, 1992. 
ROTZ, C.A.; MUCK, R.E. Changes in forage quality during harvest and storage. In: FAHEY Jr., G.C.; MOSER, L.E.; MERTENS, D.R. et al. (Eds.) National conference on forage quality, evaluation, and utilization. Madison: University of Nebraska, 1994. p.828-868.

STATISTICAL Analysis Sistem - SAS Institute Inc. SAS User's guide: statistics. Ver. 5.ed., SAS Inst., Cary, NC, 1985.

SOUZA, L.C.; ZAMBOM, M.A.; RADIS, A.C. et al. In: ABZ/UFT. Desenvolvimento de microorganismos no resíduo úmido de cervejaria "in natura"e ensilado. Resumos... Palmas, TO, 2010.

SPRAGUE, M.A.; LEPARULO, L. Losses during storage and digestibility of different crops as silage. Agron. J. Madison, v.57, p.425-457, 1965.

TOSI, H.; SCHOCKEN-ITURRINO, R.P.; REVAZZI, J.P. Presença de Clostridium em silagem de milho colhido em diferentes estádios de desenvolvimento. Pesq. Agropec. Bras., v.17, p.1133-1136, 1982.

UNCTAD. Conferência das ações Unidas para o Comércio e Desenvolvimento. Disponível em http://www.unctad.org/Templates/StartPage.asp? intItemID=2068. Acessado em: $12 \mathrm{dez} .2010$.
VALADARES FILHO, S.C.; ROCHA JÚNIOR, V.R.; CAPELLE, E.R. Tabelas brasileiras de composição de alimentos para bovinos. Viçosa: Universidade Federal de Viçosa, 2002. 297p.

VAN SOEST, P.J. Nutritional ecology of the ruminant. 2.ed. Cornell: Cornell University Press, 1994. 476p.

VAN SOEST, P.J.; ROBERTSON, J.B.; LEWIS, B.A. Symposium: Carbohydrate metodology, metabolism, and nutritional implications in dairy cattle. Methods for dietary fiber, neutral detergent fiber, and nonstarch polysaccharides in relation to animal nutrition. J. Dairy Sci., v.74, p.3583-3597, 1991.

WOOLFORD, M.K. Some aspects of the microbiology and biochemistry of silage making. Herbage Abstr.,v.42(2), p.105-111, 1972.

WOOLFORD, M.K. The silage fermentation. New York: Marcel Dekker,1984. 305p.

WOOLFORD, M.K. The detrimental effects of air on silage. J. Appl. Bacteriol., v.68, p.101-116, 1990. 